\title{
Investigation of Perceived Stress and Quality of Life Assessment of pharm. D. Students at Ibn Sina National College in Saudia Arabia during 2016
}

\author{
Lujain Turki Bin-Mallouh', Mohammed Gamal ${ }^{2,3^{*}}$, Ahmed A H Ali ${ }^{1}$, Mohamed E.A. Abdelrahim ${ }^{4,5}$, Mohammed Safwan Ali Khan ${ }^{6,7}$, \\ Mohammad M. Al-Sanea ${ }^{2}$, Kharrat Mohamed ${ }^{8,9}$, Mohammed Alrashed ${ }^{10}$ \\ 'Pharmacy Program, Ibn Sina National College of Medical Science, Mahgar Street 31906, Jeddah 21418, Saudi Arabia. \\ ${ }^{2}$ Pharmaceutical Chemistry Department, Faculty of Pharmacy, Aljouf University, Skaka 2014, Saudi Arabia. \\ ${ }^{3}$ Pharmaceutical Analytical Chemistry Department, Faculty of Pharmacy, Beni-Suef University, Alshaheed Shehata Ahmed Hegazy St., 62574 Beni-Suef, Egypt. \\ ${ }^{4}$ Clinical Pharmacy Department, Faculty of Pharmacy, Beni-suef University, Beni-suef, Egypt. \\ ${ }^{5}$ Clinical Pharmacy Department, Faculty of Pharmacy, Ahram Canadian University, Giza, Egypt. \\ ${ }^{6}$ Department of Pharmacology, College of Pharmacy, Aljouf University, Sakaka 2014, Aljouf Province, Kingdom of Saudi Arabia. \\ ${ }^{7}$ Department of Pharmacology, Anwarul Uloom College of Pharmacy affiliated to Jawaharlal Nehru Technological University - Hyderabad, Hyderabad 500 \\ 001, Telangana State, India. \\ ${ }^{8}$ Aljouf University, College of Science, Mathematics Department, Skaka, Kingdom of Saudi Arabia. \\ 9 University of Sfax, Sciences Faculty of Sfax, Mathematics Department, Probability and Statistics Laboratory, Tunisia. \\ ${ }^{10}$ Saint Louis College of Pharmacy (STLCOP), 4588 Parkview Place St. Louis, Missouri, USA.
}

\begin{tabular}{l}
\hline ARTICLE INFO \\
\hline Article history: \\
Received on: $30 / 11 / 2017$ \\
Accepted on: $24 / 01 / 2018$ \\
Available online: $30 / 03 / 2018$
\end{tabular}

Key words:

pharm D. students, Quality

life, Saudi Arabia, Stress.

\begin{abstract}
Objective. The aim of present study was to investigate the perceived stress and quality of life among Pharm. D students at Ibn Sina National College (ISNC). Methods. The sample was surveyed electronically through (Google document) that was sent to students through the email. Pharm D students from the last three professional years were invited to participate in our study. Results. Out of 209 eligible students, $52.6 \%(\mathrm{~N}=110)$ completed the questionnaire. The average age of the participants was $22.3 \pm 2.5$ years, $78.2 \%(\mathrm{~N}=86)$ of which were females and $21.8 \%(\mathrm{~N}=24)$. Students reported that they were sometimes out of control during a month period with regards to the following (with $\mathrm{p}<0.001$ ), they faced difficulty in successful dealing with problems. Conclusion. Although stress has a major role in student's life, none of the results had a negative effect on the student's quality of life. About $51 \%$ of pharm D students experienced negative symptoms quite often such as blue mood, despair, anxiety and depression. The male students reported lower perceived stress level than female. Perceived stress is not GPA score dependent. No Relation was found between the stress and year of study.
\end{abstract}

\section{INTRODUCTION}

Stress is the feeling of being under excessive intellectual or emotional pressure (Marshall et al., 2008). It is a term often used by individuals in a variety of social, academic, and employment settings. Both negative and positive aspects of a person's life

*Corresponding Author

Mohammed Gamal; E-mail: mgamalm3000@yahoo.com can contribute to stress and stress does not necessarily result in negative outcomes (Marshall et al., 2008). Stress is one of the psychological disorders that has high prevalence and re-occurrence nature, having the ability to affect any group of a population. It is the body's way of responding to exceeding amounts of demand, and those demands differ from an individual to another. As stated in the Biopsychosocial Model, stress includes three main components: an external factor (environment), an internal one (physiological and biochemical factor in one's body) and finally the correlation between the external and internal factors 
(Riffat et al., 2013; Votta and Benau, 2013; Bernard and Krupat, 1994). University students are most likely to experience different amounts and types of stress. Such amounts can affect the student's life positively or negatively. Moreover, stress contributes in affecting their academic lives, grades, level of thinking and attention during classes. In addition to that, stress can contribute in affecting the student's emotional (depression, anxiety and sadness) and health outcomes (self-satisfaction, quality of life and performance) and all of these can occur at different times during a semester or years of college, and during the transition from pre-professional year to professional year. In studies conducted in 2009 and 2014. It was found that perceived stress is higher in college students when compared to the general population (Brougham et al., 2009; Kumari and Mishra, 2014; Dutta et al., 2006). Indeed, students of healthcare professions (medical, dental, nursing and pharmacy students) reporting high and more harmful levels of stress than other students (Landow, 2006; Shah et al., 2010). The most observed reasons behind academic and psychosocial stress among medical students in a Pakistani Medical School were family expectations, frequent examinations and expansion of academic curriculum (Shah et al., 2010). Generally, the perceived stress among pharmacy students in public Malaysian universities was the same as in private ones (Alshagga et al., 2017). Furthermore, Academic-related stress was prominent in public university, while life-related stress was highly observed in private one (Alshagga et al., 2017). Effect of gender on feeling perceived stress was described in many studies with variable results (Riffat et al., 2013; Kumari and Mishra, 2014; Shah et al., 2010; Asani et al., 2016). Perceived stress was more significant in students whose fathers are educated if compared to students from uneducated backgrounds (Asani et al., 2016). There is no significant difference between the perceived stress between UK pharmacy program students and US pharmacy program students (Gallagher et al., 2014). In recent study (Hemavathi and Archana, 2017) conducted in 2017, Many techniques were suggested to cope with academic stress like meditation, breathing exercise, music, practicing yogasans, swimming and getting in touch with family and friends. Music was the first choice for medical students (about 76\%) to cope with stress (Zareena, 2017). Ibn Sina National college is one of few institutes which offers Pharm D program in KSA, Pharm D program is clearly different from the old traditional pharmaceutical sciences one as it is more patient orientated (Erdogan et al., 2012). Study includes preparatory year, 4 years ( 8 levels) and final year of training in hospital pharmacy. The pharmacy college is composed of two main departments: pharmaceutical sciences department and clinical and pharmacology department. Pharm D program was accredited by National Commission for Academic Accreditation and Assessment (NCAAA) in 2016. Study is in credit hours system. Students grade was calculated according to GPA 5 points scale analysis. According to ISNC bylaws, First class honors is granted to students who obtained GPA (4.75) to (5.00) out of (5.00). A student shall be denied from entering the final exam provided that attendance percentage is not less than $75 \%$ in lectures and practical lessons assigned for each course during the semester. Student who gets score less than $60 \%$ is considered failed and he should repeat the course again. Students in youth stage (group age from 15-25) are the most addict group of Captagon especially during exams (Bamofleh et al., 2017). And so, this pilot study aims to investigate the perceived stress and Quality of life for Pharm. D. students at Ibn Sina National College (accredited private medical college in Saudi Arabia) using the Perceived Stress
Scale-14 (PSS-14) (Cohen et al., 1983) and to explore sources of stress and stress coping strategies. Work comes in line with the Accreditation Council for Pharmacy Education (Accreditation Council for Pharmacy Education, 2017) updated requirement for schools to assess perceived stress in faculty, staff and students and to evaluate the potential for a negative impact on programmatic outcomes and morale.

\section{MATERIAL AND METHODS}

This paper represents a cross-sectional study that was performed in Ibn Sina National College for Medical Studies (ISNC). Data was collected from Pharm. D students invited to participate in a study to detect stress and Health Related Quality Of Life (HRQOL) in two months at the middle of the first semester (October-November 2016). Respondents were anonymous as their names were not recorded, but survey instruments and questionnaires were numbered and collated for data analysis. Universal sampling method was used because of small sample size.

An IRB-approved multiple questions questionnaire has been organized and created using on Google Document (Google, Mountain view, California) and electronically distributed to thirdyear through fifth-year student pharmacists who were invited to participate. Electronic survey instruments were distributed at the conclusion of the 2015-2016 semester during the last required course of each Professional Year 3, third-year (P3), forth-year (P4), and fifth-year (P5) class. Students of those years have more academic courses related to pharmacotherapy and clinical pharmacy courses. The participants were asked to complete demographic data and the HRQOL in addition to the Perceived Stress Scale-14 (PSS-14) (Cohen et al., 1983) which was used due to its established validity and reliability. Participation in this study was strictly voluntary and anonymous. PSS-14 questionnaire (Cohen et al., 1983) was used without permission because it is free to use for non-profit, academic researchs and educational purposes. The surveys were used without any modification. Statistical analyses (Person Correlations and Chi-square tests) were performed using SPSS V20.

Study tools represented in a form of questionnaire, which are prepared by the researcher with the help of experts and specialists. It is formed of four main sections: The first section of this questionnaire represents personal information researched and specified by sex, age, educational level, Grade point average (GPA), the previous degree, smoking, regular sports training and the Mediterranean of transport time between home and school, etc. The second section is 13 questions about student's health related issues. While third part mainly talks about student's daily activities, the last part was PSS-14 scale (Cohen et al., 1983) to measure the stressful moments the students experienced during the last 30 days period.

\section{Reliability and validity study}

Reliability and validity of the study was calculated using the following formula:

$$
\alpha=\frac{n}{n-1}\left(1-\frac{\sum_{k=1}^{n} \sigma_{X_{i}}^{2}}{\sigma_{X}^{2}}\right)
$$

In addition to the Cronbach's alpha value calculation. Where $X=X_{1}+X_{2}+\ldots+X_{n}, \sigma_{X}$, is the standard deviation of the observed total test scores. 


\section{RESULTS}

Out of 209 eligible students, $52.6 \%(\mathrm{~N}=110)$ completed the questionnaire. Table 1 shows the participants' personal data. It shows the participants' distribution according to gender, academic level, age and the GPA. The average age of the participants was $22.3 \pm 2.5$ years, $78.2 \%(\mathrm{~N}=86)$ of which were females and $21.8 \%(\mathrm{~N}=24)$. As a general behavior female students have more enthusiasm and concentration in study than male students because of KSA Customs and traditions, this is evident from GPA score analysis of both male and female grades in most academic courses in ISNC. Target students were at P3, P4 and P5 (19\%, 27.3\% and $53.6 \%$ ) respectively. The GPA of half of the students ranges between 3.6 and 4.6. Majority of students neglected smoking and reported lower level of exercise $75 \%$ and $64 \%$ respectively. The statistical analysis program (SPSS V.21) has been used in the study in data entry and analysis, with the use of necessary statistical methods to achieve the objectives of the study. Frequencies \& Percentages, Graph and Chi-square Test were obtained.

Table 1: Demographic data of survey participants at Ibn Sina National college for Medical Sciences during October-November 2016.

\begin{tabular}{|c|c|c|c|}
\hline The question & Choices & Frequency & Percent \\
\hline \multirow{2}{*}{ Gender } & Female & 86 & 78.2 \\
\hline & Male & 24 & 21.8 \\
\hline \multirow{3}{*}{ Academic level } & $\mathrm{P} 3 *$ & 21 & 19.1 \\
\hline & $\mathrm{P} 4 *$ & 30 & 27.3 \\
\hline & P5* & 59 & 53.6 \\
\hline \multirow{3}{*}{ Age } & $20-25 \mathrm{yrs}$ & 88 & 80.0 \\
\hline & $26-30 \mathrm{yrs}$ & 21 & 19.1 \\
\hline & Above 30 yrs & 1 & 0.9 \\
\hline \multirow{4}{*}{ GPA out of 5} & $2.5-3.5$ & 32 & 29.1 \\
\hline & $3.6-4.6$ & 53 & 48.2 \\
\hline & $4.7-5$ & 17 & 15.5 \\
\hline & Less than 2 . & 8 & 7.3 \\
\hline \multirow{2}{*}{ Prior degree (other than high school) } & No & 56 & 50.9 \\
\hline & Yes & 54 & 49.1 \\
\hline Smokes cigarettes & No & 83 & 75.5 \\
\hline \multirow{2}{*}{ Regular exercise } & Yes & 27 & 24.5 \\
\hline & No & 71 & 64.5 \\
\hline \multirow{5}{*}{$\begin{array}{l}\text { Average daily commute from residence to } \\
\text { school (in minutes) }\end{array}$} & Yes & 39 & 35.5 \\
\hline & 20-35 minute & 46 & 41.8 \\
\hline & $40-60$ minute & 43 & 39.1 \\
\hline & Above $60 \mathrm{~min}$ & 10 & 9.1 \\
\hline & Less than 15 & 11 & 10.0 \\
\hline Total & & 110 & 100.0 \\
\hline
\end{tabular}

Note: The percentages in the table are rounded to the nearest decimal place,

*P3: third years students, *P4: fourth years students, *P5: fifth years students.

As shown in Table 2, 55.5\% of the participants chose Pharm D as a first choice for their study.

Table 2 shows that $56.4 \%$ of the participants' families composed of (6-8) members, while $30.9 \%$ of their families were between (3-5) members, $10 \%$ of their families had 8 members and just $2.7 \%$ were less than 3 members.
Table 2: Responses of students to questions about first choice career, numbers of family members, family income, personal expenditure, quality of life, health conditions satisfaction, negative feelings and assistance in filling survey.

\begin{tabular}{|c|c|c|c|}
\hline \multirow{4}{*}{$\begin{array}{l}\text { Was studying Pharm D your first } \\
\text { choice? }\end{array}$} & Choices & Frequency & Percent \\
\hline & No & 49 & 44.5 \\
\hline & Yes & 61 & 55.5 \\
\hline & Total & 110 & 100.0 \\
\hline \multirow{6}{*}{$\begin{array}{l}\text { Number of members in the family } \\
\text { of participants. }\end{array}$} & Choices & Frequency & Percent \\
\hline & Less than 3 persons & 3 & 2.7 \\
\hline & 3-5 persons & 34 & 30.9 \\
\hline & $6-8$ persons & 62 & 56.4 \\
\hline & Above 8 persons & 11 & 10.0 \\
\hline & Total & 110 & 100.0 \\
\hline \multirow{4}{*}{$\begin{array}{l}\text { Family income of participants } \\
\text { (per month)? }\end{array}$} & Choices & Frequency & Percent \\
\hline & $\begin{array}{c}\text { Above } 10,000 \mathrm{SAR}= \\
2,666.70 \mathrm{USD}\end{array}$ & 68 & 61.8 \\
\hline & $\begin{array}{c}\text { Below } 10,000 \mathrm{SAR}= \\
2,666.70 \mathrm{USD}\end{array}$ & 42 & 38.2 \\
\hline & Total & 110 & 100.0 \\
\hline \multirow{5}{*}{$\begin{array}{l}\text { Personal expenditure of the } \\
\text { participants per day. } \\
\text { SAR : Saudi Arabian Riyal } \\
\text { (currency), } 1 \mathrm{SAR}=0.27 \text { USD }\end{array}$} & Choices & Frequency & Percent \\
\hline & Less than $50 \mathrm{SAR}$ & 49 & 44.5 \\
\hline & $50-100$ SAR & 45 & 40.9 \\
\hline & Above $100 \mathrm{SAR}$ & 16 & 14.5 \\
\hline & Total & 110 & 100.0 \\
\hline \multirow{7}{*}{$\begin{array}{l}\text { Rating of quality of life among } \\
\text { participants. }\end{array}$} & Choices & Frequency & Percent \\
\hline & Very poor & 7 & 6.4 \\
\hline & Poor & 8 & 7.3 \\
\hline & Neither poor & 26 & 23.6 \\
\hline & Good & 55 & 50.0 \\
\hline & Very good & 14 & 12.7 \\
\hline & Total & 110 & 100.0 \\
\hline \multirow{7}{*}{$\begin{array}{l}\text { Participants responses about } \\
\text { satisfaction with respect to their } \\
\text { health condition. }\end{array}$} & Choices & Frequency & Percent \\
\hline & Very Dissatisfied & 6 & 5.5 \\
\hline & Dissatisfied & 15 & 13.6 \\
\hline & $\begin{array}{l}\text { Neither satisfied nor } \\
\text { dissatisfied }\end{array}$ & 37 & 33.6 \\
\hline & Satisfied & 41 & 37.3 \\
\hline & Very satisfied & 11 & 10.0 \\
\hline & Total & 110 & 100.0 \\
\hline \multirow{7}{*}{$\begin{array}{l}\text { Participants responses about } \\
\text { experiencing negative feelings, } \\
\text { such as blue mood, despair, } \\
\text { anxiety and depression.* }\end{array}$} & Choices & Frequency & Percent \\
\hline & Never & 10 & 9.1 \\
\hline & Seldom & 15 & 13.6 \\
\hline & Quite often & 57 & 51.8 \\
\hline & Very Often & 20 & 18.2 \\
\hline & Always & 8 & 7.3 \\
\hline & Total & 110 & 100.0 \\
\hline \multirow{4}{*}{$\begin{array}{l}\text { Participants receiving assistance } \\
\text { to fill survey form. }\end{array}$} & Choices & Frequency & Percent \\
\hline & Yes & 45 & 40.9 \\
\hline & No & 65 & 59.1 \\
\hline & Total & 110 & 100.0 \\
\hline
\end{tabular}

Note. *Responses of excellent students to negative feelings, such as blue mood, despair, anxiety and depression is described in relation with GPA in Table 6 . 
Table 2 shows that $61.8 \%$ of the participants' families' monthly income was more than $(10,000)$ Riyal (1 Riyal $=0.27$ USD), while $38.2 \%$ of their income was less than $(10,000)$ Riyal. The average income in Saudi Arabia is greatly different depending on education level, nature of job, geographical region and governmental or private sector. The starting salary for pharmacist in governmental hospital is about 10 thousand Saudi Riyal.

Table 3: Responses to thirteen questions about student's health related issues.

\begin{tabular}{|c|c|c|c|c|c|c|c|}
\hline \multirow[b]{2}{*}{ Question } & \multicolumn{5}{|c|}{ Percentages of Answers } & \multirow[b]{2}{*}{$\begin{array}{c}\text { Rel. } \\
\text { weigh }^{1}\end{array}$} & \multirow[b]{2}{*}{ The level $^{2}$} \\
\hline & Not at all & A little & $\begin{array}{l}\text { A moderate } \\
\text { amount }\end{array}$ & $\begin{array}{l}\text { Very } \\
\text { much }\end{array}$ & $\begin{array}{l}\text { An extreme } \\
\text { amount }\end{array}$ & & \\
\hline $\begin{array}{l}\text { To what extent do you feel that physical pain prevents you from doing what you } \\
\text { need to do? }\end{array}$ & 14.5 & 19.1 & 48.2 & 15.5 & 2.7 & $54.55 \%$ & A moderate amount \\
\hline $\begin{array}{l}\text { How can you evaluate your need for any medical treatment to function in your } \\
\text { daily life? }\end{array}$ & 31.8 & 32.7 & 27.3 & 6.4 & 1.8 & $42.73 \%$ & A little \\
\hline How much do you enjoy life? & 7.3 & 10.0 & 38.2 & 36.4 & 8.2 & $65.64 \%$ & A moderate amount \\
\hline To what extent do you feel your life to be meaningful? & 6.4 & 14.5 & 34.5 & 39.1 & 5.5 & $64.55 \%$ & A moderate amount \\
\hline How well are you able to concentrate? & 6.4 & 8.2 & 59.1 & 24.5 & 1.8 & $61.45 \%$ & A moderate amount \\
\hline How safe do you feel in your daily life? & 4.5 & 9.1 & 39.1 & 34.5 & 12.7 & $68.36 \%$ & Very much \\
\hline How healthy is your physical environment? & 7.3 & 14.5 & 52.7 & 19.1 & 6.4 & $60.55 \%$ & A moderate amount \\
\hline Do you have enough energy for everyday life? & 8.2 & 19.1 & 44.5 & 26.4 & 1.8 & $58.91 \%$ & A moderate amount \\
\hline Are you able to accept your bodily appearance? & 4.5 & 25.5 & 40.0 & 27.3 & 2.7 & $59.64 \%$ & A moderate amount \\
\hline Have you enough money to meet your needs? & 6.4 & 12.7 & 48.2 & 28.2 & 4.5 & $62.36 \%$ & A moderate amount \\
\hline How available to you is the information that you need in your day-to-day life? & 4.5 & 9.1 & 60.0 & 23.6 & 2.7 & $62.18 \%$ & A moderate amount \\
\hline To what extent do you have the opportunity for leisure activities? & 4.5 & 19.1 & 60.9 & 13.6 & 1.8 & $57.82 \%$ & A moderate amount \\
\hline How well are you able to get around? & 3.6 & 18.2 & 55.5 & 20.0 & 2.7 & $60.00 \%$ & A moderate amount \\
\hline
\end{tabular}

${ }^{1}$ The relative weight $=($ mean $\times 0.2) \times 100 \% .{ }^{2}$ The level by Quintet Likert scale: $(20-35.8 \%)$ Not at all, $(36-51.8 \%)$ A little, $(52-67.8 \%)$ A moderate amount, $(68-83.8) \%$ Very much, (84-100\%) An extreme amount.

Table 2 shows that $44.5 \%$ of the participants spent daily less than (50) Riyal, while $40.9 \%$ of them spent (50-100) Riyal daily and $14.5 \%$ of them spent more than (100) Riyal daily.

Table 2 shows that, $50 \%$ of the participants described their standard of living as good, $23.6 \%$ of them had middle standard of living, $12.7 \%$ had very good standard of living, $7.3 \%$ described themselves as poor people and $6.4 \%$ said that they are very poor.

Table 2 shows that $37.3 \%$ of the participants were satisfied with their health, $33.6 \%$ said that they were neutral in their health satisfaction, $13.6 \%$ were not satisfied with their health, $10 \%$ were completely satisfied and $5.5 \%$ were completely unsatisfied.

Table 2 shows that $51.8 \%$ of the participants said that sometimes they have negative energy emotions as feeling depressed, disappointed and worried. While $18.2 \%$ of them said that they are often have these negative emotions, $13.6 \%$ of the participants are rarely have negative emotions and $3.7 \%$ of them said that they are always feeling these negative emotions.

Finally, Table 2 shows that $59.1 \%$ of the participants had no one to help them during answering the questionnaire questions, while $40.9 \%$ of them had help in answering the questionnaire. English is the second language after Arabic in KSA. Some of students were asking about meaning of some words because of limited vocabulary. Furthermore some questions were not clear enough to a few students.

So, we found that $44.5 \%$ of students didn't choose Pharm. D program as a first choice, $61.8 \%$ of respondents families had income higher than $10,000 \mathrm{RS}, 50 \%$ of the participants described their living level as good and $37 \%$ of the participants were satisfied with their health. One of questions that we targeted in our research was to evaluate negative symptoms (such as blue mood, despair, anxiety and depression) and we found that $51 \%$ of students experienced such symptoms quite often.

When they were asked about physical pain that prevents them from doing what they do, we found that the relative weight of responses was $54.55 \%$, which gives an indication "A moderate amount" as mentioned in Table 3. In other words, the body pain was a factor that prevented the participants from doing what they wanted to do, and this requires much more health caring efforts from the national health organizations toward their citizens to keep them able to do their works as expected without any obstacles. When it came to the second question titled "How much do you need any medical treatment to function in your daily life" the relative weight was $42.73 \%$, which gives an indication of little need of cure to do their daily work. Regarding "How much do you enjoy life" the relative weight was $65.64 \%$, which gives an indication of the moderate level of enjoying the life among the participants, the routine and stress of the life may be the main culprit why there are less members enjoying their lives as shown in Table 4. The fourth question "To what extent do you feel your life to be meaningful" has A moderate amount relative weight of $64.55 \%$. The fifth question of "How well are you able to concentrate" has a moderate amount relative weight of $61.45 \%$. For the sixth question which asked "How safe do you feel in your daily life?" the relative weight was $68.36 \%$, which gives an indication of the result "Very much". When the participants were asked how healthy their physical environments were; if they had 
enough energy for everyday and if they were able to accept their bodily appearance, their answers had relative weight of a moderate amount. The relative weight while answering these questions were $60.55 \%, 58.91 \%, 59.64 \%$, respectively. Regarding "Have you enough money to meet your needs?", "How available to you is the information that you need in your day-to-day life?", "To what extent do you have the opportunity for leisure activities?" and "How well are you able to get around?", the relative weights were $62.36 \%, 62.18 \%, 57.82 \%$ and $60 \%$ respectively. All gives an indication of a moderate amount result.

Table 4: Responses to ten questions about student's daily activities.

\begin{tabular}{|c|c|c|c|c|c|c|c|}
\hline \multirow{2}{*}{ Question } & \multicolumn{5}{|c|}{ Percentages of Answers } & \multirow{2}{*}{ Rel. weigh ${ }^{3}$} & \multirow{2}{*}{ The level ${ }^{4}$} \\
\hline & Very dissatisfied & Dissatisfied & Neutral & Satisfied & Very satisfied & & \\
\hline How satisfied are you with your sleep? & 10.0 & 15.5 & 34.5 & 33.6 & 6.4 & $62.18 \%$ & Neutral \\
\hline How satisfied are you with your ability to perform your daily living activities? & 7.3 & 18.2 & 32.7 & 40.0 & 1.8 & $62.18 \%$ & Neutral \\
\hline How satisfied are you with your capacity for work? & 5.5 & 16.4 & 34.5 & 38.2 & 5.5 & $64.36 \%$ & Neutral \\
\hline How satisfied are you with your abilities? & 8.2 & 12.7 & 41.8 & 29.1 & 8.2 & $63.27 \%$ & Neutral \\
\hline How satisfied are you with your personal relationships? & 6.4 & 12.7 & 30.9 & 37.3 & 12.7 & $67.45 \%$ & Neutral \\
\hline How satisfied are you with your sex life? & 10.0 & 19.1 & 38.2 & 25.5 & 7.3 & $60.18 \%$ & Neutral \\
\hline How satisfied are you with the support you get from your friends? & 4.5 & 9.1 & 35.5 & 39.1 & 11.8 & $68.91 \%$ & Satisfied \\
\hline How satisfied are you with the conditions of your living place? & 8.2 & 8.2 & 36.4 & 34.5 & 12.7 & $67.09 \%$ & Neutral \\
\hline How satisfied are you with your access to health services? & 7.3 & 14.5 & 40.9 & 32.7 & 4.5 & $62.55 \%$ & Neutral \\
\hline How satisfied are you with your mode of transportation? & 6.4 & 20.0 & 39.1 & 30.0 & 4.5 & $61.27 \%$ & Neutral \\
\hline
\end{tabular}

${ }^{3}$ The relative weight $=(\operatorname{mean} \times 0.2) \times 100 \% .{ }^{4}$ The level by Quintet Likert scale: $(20-35.8 \%)$ Very dissatisfied, $(36-51.8 \%)$ Dissatisfied, $(52-67.8 \%)$ Neither satisfied nor dissatisfied, (68-83.8)\% Satisfied, (84-100\%) Very satisfied.

Table 5: Responses to fourteen questions of Perceived Stress Scale-14 (PSS-14)a .

\begin{tabular}{|c|c|c|c|c|c|c|c|}
\hline \multirow{2}{*}{ Questions } & \multicolumn{5}{|c|}{ Percentages of Answers } & \multirow{2}{*}{$\begin{array}{c}\text { Rel. } \\
\text { weigh }^{5}\end{array}$} & \multirow{2}{*}{ The level $^{6}$} \\
\hline & Never & Almost Never & Sometimes & Fairly Often & Very Often & & \\
\hline $\begin{array}{l}\text { In the last month, how often have you been upset because of something that happened } \\
\text { unexpectedly? }\end{array}$ & 13.6 & 15.5 & 44.5 & 17.3 & 9.1 & $58.55 \%$ & Sometimes \\
\hline $\begin{array}{l}\text { In the last month, how often have you felt that you were unable to control the important } \\
\text { things in your life? }\end{array}$ & 7.3 & 10.9 & 42.7 & 30.9 & 8.2 & $64.36 \%$ & Sometimes \\
\hline In the last month, how often have you felt nervous and "stressed"? & 4.5 & 10.9 & 40.9 & 27.3 & 16.4 & $68.00 \%$ & Fairly Often \\
\hline $\begin{array}{l}\text { In the last month, how often have you dealt successfully with day to day problems and } \\
\text { annoyances? }\end{array}$ & 3.6 & 8.2 & 59.1 & 24.5 & 4.5 & $63.64 \%$ & Sometimes \\
\hline $\begin{array}{l}\text { In the last month, how often have you felt that you were effectively coping with import- } \\
\text { ant changes that were occurring in your life? }\end{array}$ & 5.5 & 8.2 & 60.0 & 20.9 & 5.5 & $62.55 \%$ & Sometimes \\
\hline $\begin{array}{l}\text { In the last month, how often have you felt confident about your ability to handle your } \\
\text { personal problems? }\end{array}$ & 2.7 & 10.9 & 52.7 & 20.9 & 12.7 & $66.00 \%$ & Sometimes \\
\hline In the last month, how often have you felt that things were going your way? & 5.5 & 13.6 & 54.5 & 19.1 & 7.3 & $61.82 \%$ & Sometimes \\
\hline $\begin{array}{l}\text { In the last month, how often have you found that you could not cope with all the things } \\
\text { that you had to do? }\end{array}$ & 5.5 & 10.0 & 56.4 & 20.0 & 8.2 & $63.09 \%$ & Sometimes \\
\hline In the last month, how often have you been able to control irritations in your life? & 4.5 & 11.8 & 60.0 & 19.1 & 4.5 & $61.45 \%$ & Sometimes \\
\hline In the last month, how often have you felt that you were on top of things? & 6.4 & 12.7 & 55.5 & 20.0 & 5.5 & $61.09 \%$ & Sometimes \\
\hline $\begin{array}{l}\text { In the last month, how often have you been angered because of things that happened } \\
\text { that were outside of your control? }\end{array}$ & 7.3 & 5.5 & 54.5 & 24.5 & 8.2 & $64.18 \%$ & Sometimes \\
\hline $\begin{array}{l}\text { In the last month, how often have you found yourself thinking about things that you } \\
\text { have to accomplish? }\end{array}$ & 2.7 & 11.8 & 42.7 & 20.0 & 22.7 & $69.64 \%$ & Fairly Often \\
\hline $\begin{array}{l}\text { In the last month, how often have you been able to control the way you spend your } \\
\text { time? }\end{array}$ & 4.5 & 21.8 & 45.5 & 22.7 & 5.5 & $60.55 \%$ & Sometimes \\
\hline $\begin{array}{l}\text { In the last month, how often have you felt difficulties were piling up so high that you } \\
\text { could not overcome them? }\end{array}$ & 3.6 & 12.7 & 57.3 & 19.1 & 7.3 & $62.73 \%$ & Sometimes \\
\hline
\end{tabular}

${ }^{a}$ Cohen S. PSS (English; 14 Items), Dr. Cohen’s Scales, Laboratory for the Study of Stress, Immunity and Disease. Available at: http://www.psy.cmu.edu/ scohen/. Accessed Oct 11, 2016. ${ }^{5}$ The relative weight $=($ mean $\times 0.2) \times 100 \% .{ }^{6}$ The level by Quintet Likert scale: $(20-35.8 \%)$ Never, $(36-51.8 \%)$ Almost Never, $(52-67.8 \%)$ Sometimes, (68-83.8)\% Fairly Often, (84-100\%) Very Often.

When participants were asked if they are satisfied with their sleep, ability to perform daily living activities, capacity for work, personal relationship, sex life, condition of living place, access to health services and mode of transportation, their 
answers were of neutral satisfaction amount with relative weight ranging from $60.18 \%$ to $67.45 \%$. They are clearly satisfied with the support they get from friends with a relative weight of $68.91 \%$, which gives an indication of a high degree of the participant's satisfaction about the support they get from their friends.

PSS-14 scale (Cohen et al., 1983) Table 5 was used to measure the stress level of the situations the students experience during the last month. Out of 14 questions, 12 questions involve situations that were appraised as sometimes stressful. The relative weight was ranging from $58.55 \%$ to $66.00 \%$, which gives an indication of neutral response toward the situation within the questions answered. Regarding "In the last month, how often have you felt nervous and "stressed?" The relative weight was $68 \%$, which gives an indication that the participants have often felt nervous and stressed the last month. When they asked "In the last month, how often have you found yourself thinking about things that you have to accomplish?" The relative weight was $69.64 \%$, which gives an indication that the participants had often found themselves thinking about things that they had to accomplish the last month.
Table 6: Responses of students with highest grade (GPA grade point average $=4.7-5$ ) to existence of negative feelings, such as blue mood, despair, anxiety and depression.

\begin{tabular}{ccc}
\hline Responses & Frequency & Percent \\
\hline Never & 1 & 6.67 \\
Seldom & 2 & 13.33 \\
Quite often* & $\mathbf{1 0}$ & $\mathbf{6 6 . 6 7}$ \\
Very Often & 1 & 6.67 \\
Always & 1 & 6.67 \\
\hline
\end{tabular}

Note *the highlight existence of frequent negative feelings in top performers.

Table 7: ANOVA-test between academic years and stress level.

\begin{tabular}{cccccc}
\hline Academic year & N & Mean & Std. Deviation & F-test & Sig \\
\hline P3 (Third-year) & 21 & 3.13 & .729 & 1.234 & .295 \\
P4 (Fourth-year) & 30 & 3.06 & .499 & & \\
P5 (Fifth-year) & 59 & 3.24 & .483 & & \\
Total & 110 & 3.17 & .543 & & \\
\hline
\end{tabular}

Table 8: Statistical analysis of tables 3, 4 and 5 (random variables and probability distributions).

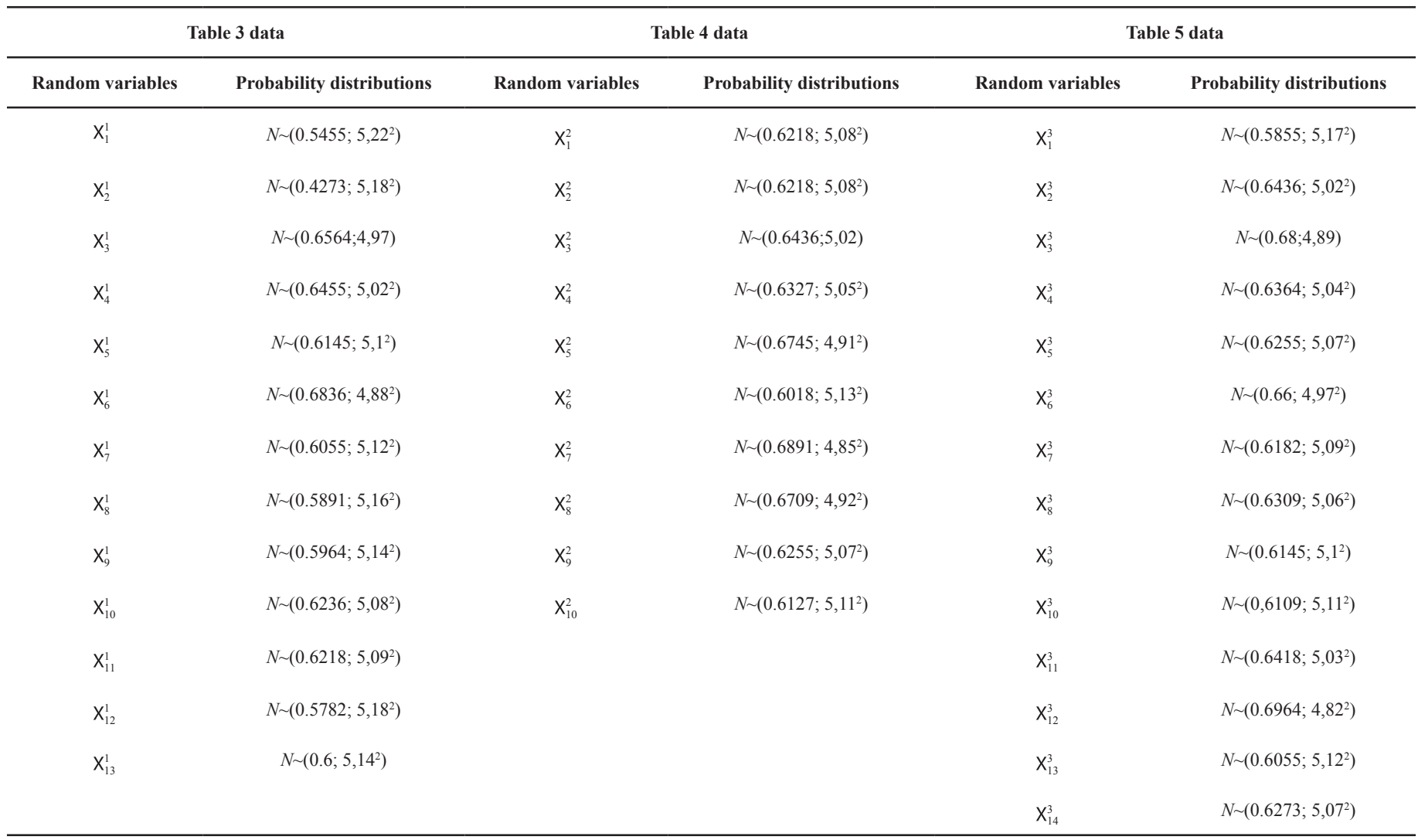

Further examination of responses of excellent students (with GPA score $=4.7-5$ ) Table 6 in all academic years to " How often do you have negative feelings, such as blue mood, despair, anxiety and depression?" indicates that the majority (about $66.67 \%$ ) of them quit often felt stress symptoms.

Relation between year of study and stress is represented in Table 7, it is clear that no statistically significant differences were observed in the stress level due to academic year.

Statistical analysis including random variable and probability distributions is shown in Table 8. From careful examination of theoretical study of the results, we remarked that all random variables are approximate to a normal distribution with expectation varies between 0.4273 and 0.6964 and with standard deviation between 4.82 and 5.22. The skewness and the 
kurtosis tests were performed and we deduced that the results are correlated with the theoretical calculus. Furthermore, we obtain an experimental expectation near to 0.5 for a normal distribution so our approximation calculus converges to the theoretical calculus.

\section{Reliability and validity study}

formula:

Basing on the previous results using the following

$$
\alpha=\frac{n}{n-1}\left(1-\frac{\sum_{k=1}^{n} \sigma_{X_{i}}^{2}}{\sigma_{X}^{2}}\right)
$$

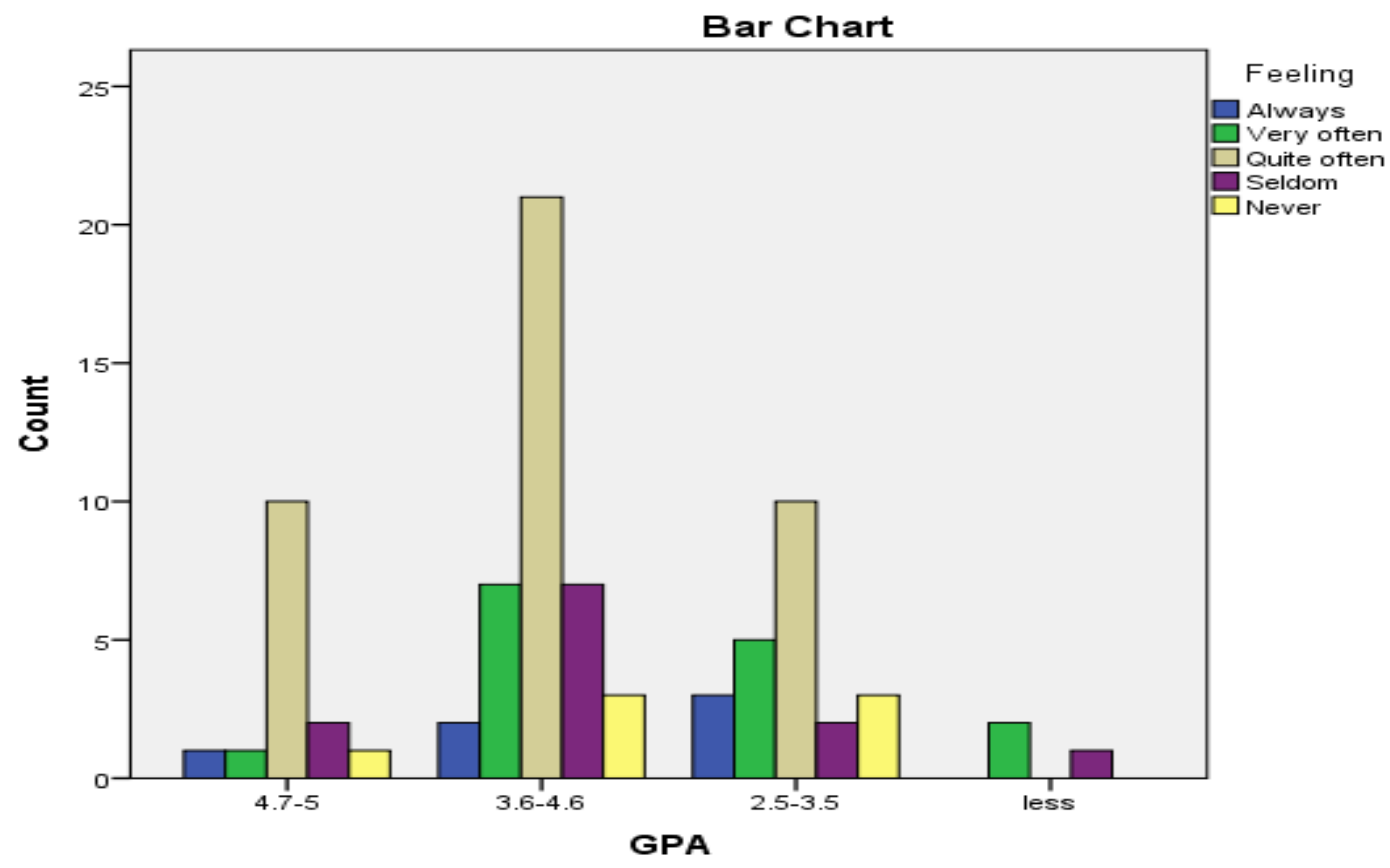

Fig. 1: Relation between responses of students to existence of negative feelings, such as blue mood, despair, anxiety and depression.

\section{DISCUSSION}

Although stress plays a major role in student's life, none of the results had a negative effect on the student's quality of life. However, students reported that they were sometimes out of control during a month period with regards to the following (with $\mathrm{p}<0.001$ ): they were feeling stressed, nervous and lack of concentration in controlling the most important things in their own lives, they could not manage their problems successfully and felt angered because of things that happened outside their control. We recommend repeating the study again in different times during a year, since most of students were free from exams during time of study. With that being said, there is a study conducted in third-year Pharm. D students at Mercer University in Georgia during 2008 (Marshall et al., 2008), 80\% of third-year students participated $(\mathrm{n}=109)$ in this pilot study. Mental health-related quality of life (HRQOL) scores were significantly below US mean score for individuals aged 20-34 years $(p<0.0001)$. Found that stress levels were significantly high and low mental HRQOL. Family and relationships, outside-of-class assignments, examinations, scheduling and monetary issues were the most common stress triggers reported by students (Marshall et al., 2008). On the other
The Cronbach's alpha value was calculated and found to equal 0.89 .

Where $X=X_{1}+X_{2}+\ldots+X_{n}, \sigma_{X}$ is the standard deviation of the observed total test scores.

For this investigations, we obtained an approximate expectation near to 0.5 for a normal distribution so our approximation calculus converges, it's due that the sample is in reality follows a binomial distribution. In our case it is symmetric and this proves the reliability and the validity of the study.

Bar Chart 
Our recommendations to overcome perceived stress, for those students who represent a high level of stress, they need to have an advisory that referred to him in case of stress during their study. For students who experiences high amount of stress, they have to organize themselves during a semester to avoid any stress during their study. The college can organize one journey per month for historic places in Jeddah, the youth center in the college can support students skills in painting, poetry and music. Also, sports competitions could be held on regular basis. Depending on each teacher how they deal with students, teachers should be patient with his students and to give them opportunities to learn without additional stress.

Limitations of this study includes conducting only a one-time measurement and inclusion of only three year of students at a private University. Our current study tried to avoid some of these limitations by conducting the questionnaire on participants of different years, however the results could be enervated by other co-variables (other than study factor itself) such as student's life, economic status and daily physical activity. Number of students was small, in term of both male and female. For such a distribution of sample, the results of study cannot be generalized over all regions of the kingdom. Moreover, time when students are stressed should be considered because students being under exams, assignments and presentation stress will report higher stress levels than those who don't have.

Another limitation of this study is shortage of information about coping with stress, hoping further studies to point out various ways of removing stress impacts in kingdom of Saudi Arabia (KSA). We expect that our students don't give priority to music as reported recently in India (Zareena, 2017) because of religious habits.

\section{CONCLUSION}

Although stress has a major role in student's life, none of the results had a negative effect on the student's quality of life. About $51 \%$ of pharm D students experienced negative symptoms quite often such as blue mood, despair, anxiety and depression. The male students reported lower perceived stress level than female. Perceived stress is not GPA score dependent. No Relation was found between the stress and year of study.

Our future recommendations is to repeat this study again at different times in different cities and universities in kingdom of Saudi Arabia. Furthermore, comparative studies for measuring perceived stress among medical team staff will be of great impact for best medical profession practice.

\section{ACKNOWLEDGMENT}

Special thanks to Ms. Reham Ahmed, for her help in primary statistical analysis of results.

\section{AUTHORS CONTRIBUTIONS}

Author 1 designed the survey, collected the results and wrote the first draft. Author 2 wrote the second draft. Author 3 did interpretation of statistical analysis. Author 4 made the first revision and submission of the paper. Author 5 revise the languge and made the final revision. Author 6 made validation study and respond to reviewer comments about statistical analysis. Author 7 made the final editing and reviewing of validation study. Author 8 helped in choosing the topic and designing the survey.

\section{COMPETING INTERESTS} publication.

No other authors report a competing interest for

\section{ETHICAL APPROVAL}

Ethics approval was not needed for this study. Generally ethical approval in KSA is required only for clinical, genetic and biological research for human and animals while no restrictions for survey based research according to executive regulations for ethics in research for human beings in KSA see link http:// bioethics.kacst.edu.sa/.

\section{REFERENCES}

Accreditation Council for Pharmacy Education Accreditation standards and guidelines for the professional program in pharmacy leading to the doctor of pharmacy degree. Accreditation Council for Pharmacy Education. https://www.acpe-accredit.org/. Accessed June 11, 2017.

Alshagga MA, Nasir NZM., Behzadnia A, Jasamai M, Al-Absi A, Al-Dubai SAR. Perceived stress and sources of stress among pharmacy students in Malaysian public and private universities: a comparative study. Pharm Edu. http://pharmacyeducation.fip.org/ pharmacyeducation/article/ view/352. Accessed June 11, 2017.

Asani M, Farouk Z, Gambo S. Prevalence of perceived stress among clinical students of Bayero University Medical School. Nigerian Journal of Basic and Clinical Sciences(NJBAS)2016;13(1):55. doi: 10.4103/0331-8540.176209.

Bamofleh EA, Mohammed JA, Abdelrahim MEA, Gamal M. The Reasons Behind Prevalence of Captagon Addiction in Jeddah and Community Awareness: A Questionnaire-Based Study. ScholReps 2017 April; 2(1)

Bernard LC, Krupat E. Health psychology: biopsychosocial factors in health and illness. Fort Worth: Harcourt Brace College Publishers; 1994.

Brougham RR, Zail CM, Mendoza CM, Miller JR. Stress, Sex Differences, and Coping Strategies Among College Students. Curr Psychol., 2009;28(2):85-97. doi:10.1007/s12144-009-9047-0.

Cohen S, Kamarck T, Mermelstein R. A global measure of perceived stress. Journal of health and social behavior; 1983, 385-396.

Dutta AP, Pyles MA, Miederhoff P. Measuring and understanding stress in pharmacy students. In: Landow MV, ed. Stress and mental health of college students. New York: Nova Science Publishers; 2006:1-28.

Erdogan ON, Erdogan MS, Gunay ONUR, Erkus S, Ulus T. Community pharmacists' perception of their clinical pharmacy service function, a study from turkey. Revista Farmacia, 2012; 60:749-758.

Gallagher CT, Mehta AN, Selvan R, Mirza IB, Radia P, Bharadia NS, Hitch G. Perceived stress levels among undergraduate pharmacy students in the UK. Curr Pharm Teach Learn., 2014; 6(3):437-441. doi:10.1016/j.cptl.2014.02.004.

Hemavathi M, Archana R. Prevalence Of Stress Among The Undergraduate Medical Students: A Cross Sectional Study. International Journal of Research in Ayurveda \& Pharmacy (IJRAP). 2017; 8(2):238-240. doi:10.7897/2277-4343.082119.

Kumari M, Mishra S. Mental stress of college students across gender. Advance Research Journal Of Social Science(ARJSS), 2014;5(2):180-183. doi:10.15740/has/arjss/5.2/180-183.

Landow MV. Stress and mental health of college students. New York: Nova Science Publishers; 2006.

Marshall LL, Allison A, Nykamp D, Lanke S. Perceived Stress and Quality of Life Among Doctor of Pharmacy Students. Article Am J Pharm Educ., 2008;72(6):137. doi:10.5688/aj7206137. 
Riffat Y, Sidra SA, Huma A, Tehseen Q, Farya Z. Prevalence of Perceived Stress among Pharmacy Students in Pakistan. Int. J. Pharm. Sci. Rev. Res., 2013; 23(2); no. 55, 343-347.

Shah M, Hasan S, Malik S, Sreeramareddy CT. Perceived Stress, Sources and Severity of Stress among medical undergraduates in a Pakistani Medical School. BMC Med Educ., 2010;10(1). doi:10.1186/1472-6920-102.

Votta RJ, Benau EM. Predictors of stress in doctor of pharmacy students: Results from anationwide survey. Curr Pharm Teach Learn., 2013;5(5):365-372. doi:10.1016/j.cptl. 2013.06.014.

Zareena S. Prevalence of stress among medical students and music to alleviate the stress. International Journal of Research in
Medical Sciences (IJRMS)., 2017;5(6):2512. doi:10.18203/2320-6012. ijrms20172438.

How to cite this article:

Bin-Mallouh LT, Gamal M, Ali AAH, Abdelrahim MEA, Khan MSA, Al-Sanea MM, Mohamed K, Alrashed M. Investigation of Perceived Stress and Quality of Life Assessment of pharm. D. Students at Ibn Sina National College in Saudia Arabia during 2016. J App Pharm Sci, 2018; 8(03): 082-090. 